\title{
Hopeless Cases? Dickens, Mendacity and Medical Earnestness: A Reading of Mr. Nightingale's Diary (1851)
}

\author{
Loredana Salis
}

Department of Humanities and Social Sciences, University of Sassari, Italy

Copyright $\bigcirc 2016$ by authors, all rights reserved. Authors agree that this article remains permanently open access under the terms of the Creative Commons Attribution License 4.0 International License.

\begin{abstract}
A peculiarity of Charles Dickens's narrative style is the use of lengthy entertaining and thought-provoking descriptions. Among them, a significant number are dedicated to meticulous accounts of accidents and illnesses which are noteworthy also because they disclose this writer's remarkable interest in and knowledge of medical matters. Dickens was a regular reader of The Lancet and a keen observer of symptoms and cures, so much so that according to an article published in the British Medical Journal in 1924 he possessed 'powers of medical observation far in advance of the clinicians of his day'. Dickens had first-hand experience of clinical cases, and there is no doubt as to his actual contribution to furthering medical knowledge. However, the full scale of his impact upon modern medicine is best appreciated when considered in the light of the medical debate of 1850s England and with regards to Dickens's place in the cultural critique of mid-Victorian England. In spite and because of his medical knowledge, Dickens was skeptical of the unquestioned authority of science and scientists, and he equally disapproved of the traditional doctor-patient relationship. This paper aims to explore these aspects from a literary perspective through a reading of a lesser-known work by Charles Dickens and Mark Lemon entitled $\mathrm{Mr}$. Nightingale's Diary (1851).
\end{abstract}

Keywords Charles Dickens, Mr. Nightingale's Diary, Mid-Victorian England, the medical debate

\section{Dickens, theatre and the medical debate: preliminary thoughts}

This paper reflects on Charles Dickens's place in the mid-Victorian medical debate and cultural milieu through a reading of Mr. Nightingale's Diary, a one-act play written in 1851 together with his friend Mark Lemon, a famous Shakespearean actor at the time and a founder of the satirical journal Punch. The play belongs to a set of seven theatre works which Dickens completed between the late 1830s and the late $1860 \mathrm{~s}$, and which remain largely unknown to the wider audience still today, both among Anglophone and non-Anglophone audiences ${ }^{1}$. As opposed to Dickens's novels and short stories, in fact, his dramatic oeuvre has not received significant attention from critics or theatre practitioners; the texts have no large production history and they have hardly been translated into languages other than the original English. The bicentenary of Dickens's birth, in 2012, helped to draw public and critical attention also to parts of his literary production which are still usually dismissed, and in such terms Dickens's plays as well as his use of the theatrical medium are central to the present argument. The anniversary celebrations saw also an increase in the number of articles and scholarly works dealing with Dickens's contribution to current medical scholarship, with special emphasis on the accuracy of descriptions of symptoms and a variety of physical ailments which form part of our contemporary medical encyclopedia $[1,2,3]$. Those works, mainly by medical experts, offer eloquent examples from a variety of Dickensian texts, shedding new light on medical matters but ultimately failing to go beyond the description of symptoms and physical ailments, therefore hardly exploring the revealing narrative value of Dickens's engagement with such matters. None of those articles ever makes citations from Dickens's plays, which, in fact provide a wealth of material for literary investigation. Over the past three decades scholars have taken up the task of considering the narrative potential of diseases and diagnoses exploring the notion of 'illness as a metaphor', to recall the title of Susan Sontag's pioneering work $^{2}$. Their studies provide a methodological basis for in-depth readings of literary texts featuring doctors and patients as well as symptoms and cures.

1 The plays are: The Strange Gentleman and The Village Coquettes, both dated 1836; Is She His Wife?(1837); The Lamplighter (1838); Mr. Nightingale's Diary (1851); The Frozen Deep (based on Wilkie Collins' namesake short story; 1857); and No Thoroughfare (1867).

2 To cite some examples: S. Sontag, Illness as Metaphor. New York: Vintage Books, 1979; S. Felman, Writing and Madness. Ithaca, NY: Cornell U.P., 1985; S. Gilman, Disease and Representation: Images of Illness from Madness to AIDS. Ithaca, NY: Cornell U.P., 1988; A. Vrettos, Somatic Fictions. Imagining Illness in Victorian Culture. Stanford: Stanford U.P., 1995; M. Logan, Nerves and Narratives. London: University of California Press, 1997; K. Byrne, Tuberculosis and the Victorian Literary Imagination. Cambridge: CUP, 2011. F. Kaplan, Dickens and Mesmerism. The hiddenSprings of Fiction, (here [6]) partly belongs to this category of works. 
When it comes to Dickens, though, there seem to be no references to his plays or to his endeavor to spark debate on the limits and the dangers of unquestioned medical discourse. Moreover, when scholars approach the question of Dickens's actual contribution to social reform, they tend to focus on children's poor health but dismiss the validity of his medical narratives as testimonies of his actual and broader output. A recent article by the BBC News Magazine online, published on Dickens's birthday, on $7^{\text {th }}$ February, is exemplary in this respect: posing a rhetorical question - 'Did Charles Dickens really save poor children and clean up the slums?' - and relying on authoritative voices from academia (e.g. Malcolm Andrews, editor of the Dickensian Journal of the Dickens Fellowship; Heather Shore, a social history expert at Leeds Metropolitan University; Hugh Cunningham, professor of social history at the University of Kent), the article draws the conclusion that in fact Dickens did not help change things [1]. Contrary to such opinion, this study contends that Dickens did change things, and that he managed to do so also from the stage, through a medium which afforded him constant experimentation, and a direct contact with his public whose response, both emotional and intellectual, he was able to record immediately. Accordingly, what follows combines the unquestionable merit of Dickens's medical interest, his engagement with medical discourses and the validity of theatrical practice through an almost forgotten farce, Mr. Nightingale's Diary.

\section{Dickens: literary creativity and medical practice}

Theatrical experimentation proved to be functional to the writer's debate on matters concerning medicine and its authoritative place in mid-Victorian culture and society. $M r$. Nightingale's Diary, notably a minor work in the Dickens canon, provides an alternative look at contemporary medical debates and it contributes to a better understanding of this writer's endeavor towards social and medical reforms. As I wish to contend, Dickens satirized popular medical practices to deal with the largely unquestioned authority of medicine and pursue scientific advancement in the interest of patients and their health, against common mendacious and patronizing discursive practices.

Dickens engaged keenly with the theatre. As a young man he had tried to become an actor, and throughout his life he never stopped writing for the stage, constantly exploring the multiple languages of theatre. ${ }^{3} \mathrm{He}$ was also a skilled observer of both symptoms and cures, and took a significant interest in alternative medical practices which were gaining

3 The aspect of theatre and the theatricality of Dickens's work is beyond the scope of the present study, but in this context it may be recalled that theatre was for Dickens like a lens and a special idiom through which he viewed and recounted reality. Highly influenced by Shakespeare, Dickens also adopted and adapted the monopolylogue technique he had learnt from actors Charles Mathews and Albert Smyth and used it for his 'readings', live performances of texts which he reworked for those occasions and which he toured in Europe and America until a few months before he died $[12,13]$. popularity in England in the late 1840s. An avid reader of The Lancet, an influential medical journal 'founded ... for the purpose of exposing the abuses of corrupted and contended professionalism' [6: 29-30], Dickens learnt how to treat symptoms such as anxiety and insomnia through mesmerism, a technique he learnt from a well-known practitioner, Doctor John Elliotson (1791-186 ${ }^{4}$. Mesmerism, or animal magnetism, enabled one person to influence another person's mind by augmenting the mental powers of the mesmeric subject [14: 609]. Endorsing Elliotson's brand of mesmeric practice, Dickens improved his skills and had several chances to test his powers: in the mid-1840s, while he was travelling through Italy, and on a number of occasions, he treated his friend Augusta de la Rue, who suffered from a complex of symptoms including headaches, insomnia, tics, and convulsions [15: 7] as well as his own wife, who suffered from post-natal depression [2: 308]. Detailed accounts of those trance sessions are found in his correspondence [16:247-248] and, more importantly for us here, they are wisely crafted and reworked within Dickens's stories and plays: the regular practice of mesmerism, in other words, inevitably nourished and flowed into his creative work while also giving him an opportunity to improve his own progress as a self-made medicine man.

Mesmerism was one of different alternative healing techniques which entered the public and medical spheres in mid-Victorian England. Another one was hydropathy, also called 'the cold water cure', which became popular in the $1840 \mathrm{~s}$ and was dubbed by the official medicine as an 'irregular' [8] or 'unorthodox' [9] medical approach. Like mesmerism, hydropathy was strongly attacked by doctors who sought to expunge it by medical reform [14: 600]. Hydropathy consisted of regular cold water intake as well as external use through wet blanket wraps and cold showers. Combined with rest, a controlled diet, exercise and abstinence from alcohol, this therapy promised to treat incurable cases with no recourse to drugs or chemicals. Early in 1851 Dickens visited Malvern Wells, Britain's first hydro, with his wife, who was admitted there for a course of hydropathy [7]. The experience was highly beneficial to Mrs. Dickens, who claimed to feel 'a great deal better' already a week from arrival [7], and it certainly proved resourceful for her husband, who shortly began to write a play set there, at Malvern, in the present [10].

\section{Mr. Nightingale's Diary}

While at Malvern Dickens started working on a farce to be entitled Mr. Nightingale's Diary, an enterprise that kept him busy through a difficult time of his life during which he lost his father and, two weeks later, his daughter. He sought the help of a farceur such as Lemon was, and by May 1851 the work was complete. Mr. Nightingale's Diary tells the story

4 Dickens presumably met Dr. Elliotson as early as 1837 . He became the family doctor and the two shared a lasting friendship [6:29]. 
of the eponymous character, who is a water patient at Malvern Wells, and a very special one too since he hasn't 'known a day's health these twenty years' [10: 49]. A hypochondriac in search of a cure that does not exist, Nightingale wonders 'whether there is anything that would do me good. I have tried hot water and hot mud and hot vapor and have imbibed all sorts of springs from zero to boiling, and have gone completely through the pharmacopoeia; yet I don't find myself a bit better.' [10: 33]

The protagonist keeps a Diary which records a historiography proper of the patient's long-term ailments: even the tiniest symptom is described there, meticulously and with careful attention to type, recurrence and spreading of symptoms:

Here! Refer to the Diary (Gives book). Rosina ... see last Tuesday ... What's the afternoon entry?

Rosina, Nightingale's young nephew, reads:

New symptom.Crick in back. Sensation as if Self a stiff boot-jack suddenly tried to be doubled up by strong person... Symptom repeated, sir?

To which Nightingale replies:

Symptom repeated. I must put it down ... (Nightingale takes the book on his knees and writes) 'Symptom repeated.' - O! (starts again) 'Symptom re-repeated ...Lord bless me! Boot-jack and strong person contagious! ...'Symptom shortly afterwards repeated in niece!' [10: 29-30]

The 'Diary', significantly spelt with capital D in the text, represents Nightingale's only comfort; for him it is a quasi-bible he literally lives by. Dickens uses the 'precious volume' [10: 35] as an example of the erratic nature of the empirical gaze upon which the institute of the medicine of science largely rested. All diagnoses are based on observation, in other words. Such a methodology of tracing cause and effect was crucial to other fields of knowledge, including history and police investigations, and it was also central to the logic of realist narratives, despite its evidently limited episteme it still retained a powerful place also in medical approaches of the time [11]. The play's Diary is a record of observed symptoms (and an exposure of the cause-effect strategy) but it also represents an ironic reminder of the way the Victorians had become 'almost obsessed by the possibility of curing all illnesses' [6: 8]. The nineteenth century saw the proliferation of medical works (textbooks, manuals, photographic evidence, essays and articles, journals, etc...) which contributed to medical doctrine an almost religious status at the time, with many among patients hardly questioning their physicians, in whom they trusted blindly. Viewed in these terms Mr. Nightinghale embodies a complex web of discourses which Dickens sets out to expose and eventually discard.

The Diary, which is dubbed 'the book' in the play, informs us that sometimes back in the 1830s Nightingale turned from patient to an invalid proper: 'You must know I am an invalid', he is adamant about telling one of the characters [10:49]. His present status and the reality of being an invalid indicates how the protagonist achieves (and accepts) a peculiarly vulnerable condition that places him in the hands of the so-called medical experts. To complicate matters, in a farcical way, Dickens has Nightingale depicted as a 'hopeless case' [10: 164], that is to say a man who has 'nothing the matter' with him, but won't be persuaded to feel otherwise. The words are uttered by Thomas Lithers, the landlord of the Malvern establishment, and possibly Dickens's alter-ego in the play, who thus depicts Nightingale as a man 'particularly attentive to the state of [his] own health, even to the smallest change of feeling in their bodies, and from any unusual sensation, perhaps of the slightest kind, [he apprehends] great danger, and even death itself'. An hypochondriac by definition, Nightingale suffers from a condition that includes physical symptoms (affecting especially the lower abdomen) as well as mental delusions. The 'unfounded belief that one is sick', as hypochondria was defined in 1816 , by the 1830 s became a mere form of 'morbid melancholy' [14].

Lithers never talks about or pretends to be an authority on health matters, in fact he shares little with the other characters, who, conversely, claim to be (or to have been) ill, or else they act as medical experts and dispense miracle cures that could hardly work. All characters, except Lithers, take up false identities; they cheat and are cheated in turn. Laughter, of course, is guaranteed, and so is spectacle, and indeed the play, which premiered at Devonshire House on 27 May 1851, was a huge success, touring the country with about twenty performances in 18 months. As it is typical of Dickens, however, laughter comes at the expense of small epiphanies on the part of the audience, so that what appears to be pure entertainment often turns out to provoke second thoughts. In performance great attention was given to the tiniest detail: Dickens looked after script, acting, mise-en-scene, stage setting and all aspects concerning the play's production $[12,13]$. A complete theatre practitioner, he knew that the reception of a play and ultimately its success were highly dependent on a wise balance between all those elements. This was evident in the production of $M r$. Nightingale's Diary, a full-costume performance which relied on travesty and swapped or faked identities to convey its message.

In the play a man named Slap shows up as Flormiville, who is a quack physician; another, called Gabblewig acquires multiple identities - he becomes Mr. Poulter, then Captain Blower, a respectable female and a deaf sexton, but he is ultimately a lawyer and a man with a broken-heart seeking remedy through hydropathy [10: 94]. Another character, named Tip, pretends to be Mrs. Nightingale's lost child [10: 83], Nightingale's nephew, the young Rosina, acts as Mrs. Poulter and then as a nurse called Mrs. Trusty [10: $56,64]$. Travesty proves to be functional to farce as well as to the play's representation of a world in which mendacity rules, and medicine, with its 'men of science', is itself nothing but mendacity in disguise. 


\section{Dickens and the medical debate}

\subsection{Patients and invalids}

It has been noted how among those present at Malvern Nightingale is the only real 'patient' and the one everybody treats as an invalid. Both terms - 'patient' and 'invalid' would certainly strike a chord with Victorian audiences at the time, when a collection of essays entitled Life in the Sickroom by the journalist (and patient) Harriet Martineau became a popular read. Published in 1844, this influential volume contributed to debates on 'the would-be hegemony of medical orthodoxy', in defense of the authenticity of the patient's opinion against the eroding forces of modern medicine [15]. Martineau (1802-1876) wrote out of her personal experience as a long-term patient diagnosed with a tumor and successfully treated with mesmerism, the controversial yet innovative and, in her view, successful approach to healing. Today an almost forgotten book, Life in the Sickroom was influential in contemporary discussions on the culture of invalidism. Its innovative quality rests on it giving voice to the silenced sufferer, often reduced to being an invalid who is "wholly at the mercy of those who speak of us' [16: 44]. Those surrounding the sick think they can bring them solace but they are wrong, for 'Who can console?' asks Martineau, and 'How is it possible to please and soothe the sufferer', really? [16: 25]. Dickens would have met Martineau years before her pioneering work was published: in the late 1830 s they attended the same literary circles, and like other eminent Victorians including Thackeray, Macready, Trollope, and John Foster, Dickens's friend and future biographer, they both took interest in and practiced Elliotson's mesmerism [4: 23]. Years on, in the 1850s, following his invitation, Martineau would also become a regular contributor to his Household Words. Though there is no guarantee that Dickens read the Essays, doubtlessly the long-term relationship between them led to a receprocal influence.

\subsection{Dickens's medical knowledge}

Dickens's medical knowledge was not exceptional for the time in which he lived. Victorian England, as noted, produced a wealth of literature including manuals such as 'conduct', 'courtesy' and 'etiquette' books for the making of the perfect gentleman and the impeccable woman. The health of the individual meant necessarily the health of the nation, thus it is little surprise that manuals would insist on their readers' acquisition of medical and healthcare skills. The pursuit of a healthy lifestyle through physical exercise, cleanliness, a balanced diet, and access to first-aid remedies for relatively minor ailments was the staple of middle- and upper-class education to the point where it was regarded as a 'moral duty' [19: 12]. There was a general obsession with health and a distinctive fear of disease ${ }^{5}$, epitomised in Mr. Nightingale and in his diary entries as well as in the man's belief that essentially everyone is ill: 'You are ill, if only you knew it', he tells a maid; 'If you were as intimate with your own interior as I am with mine, your hair would stand on end' [10:169]. His preoccupation, just like the average Victorian's preoccupation with health matters engendered distinctive tendencies towards that 'groundless morbid fear for one's health' [14] which affects Nightingale and which was a 'real and sad disease ... unhappily in England very frequent' [20].

\subsection{Mr. Nightingale's Diary and the medical debate in mid-Victorian times}

Nightingale's conviction that he is 'intimate with his interior' reveals a peculiar view of medicine in holistic terms such that the mind and the body are no longer seen as two separate entities. By contrast, traditional medicine, that is to say biomedicine, "viewed the body as a machine, the functioning of which is determined by biological and scientific laws' [21: 5]. This reductionist paradigm assumes that any dysfunction can be repaired because all disease originates from specific and knowable causes but it fails to acknowledge that health is influenced by both social and psychological factors [22: 23]. In 1851, when the play was written and performed, biomedicine was undergoing significant changes in the attempt to deal with the inadequacy of its current system, which was often and convincingly exposed ${ }^{6}$. In this respect, the mind-body split and the practice of hydropathy in the play are emblematic of that deficient medical orthodoxy denounced by Martineau, among others, at the time. In a crucial scene Dickens has a character named Gabblewig 'enter with a very large tumbler of water' for Nightingale, the water patient, but Slap, who is 'dressed as a smug physician' stops him:

Slap: Rash man, forbear! Drain that chalice, and your life's worth a bodkin.

Nightingale: Dear me, Sir! It's only water. I am merely a pump patient.

Slap: Persevere, and twelve men of Malvern will sit upon you in less than a week, and without retiring, bring a verdict of 'Found Drowned' [10: 52].

Disguised as a doctor, Slap denies hydropathy any validity.

5 The fear of contagion was due largely to the awareness that diseases easily spread among the lower classes, forced to live in poor sanitary conditions, subject to long working hours in unhealthy contexts, not to mention food deprivation and physical consumption. Any source of contagion was isolated and the poor put together in workhouses, dreadful institutions providing basic food and accommodation first established under the Poor Laws during the reign of Elizabeth I and usually located in peripheries. In 1834 the New Poor Law was passed which turned the workhouse into 'a place of bleak deterrence ... designed to be deliberately uncongenial' [3: 404), which Dickens publicly attacked and portrayed in Oliver Twist (1838).

6 Early medical theories of hysteria maintained that the womb of hysterical women moved around the body [19:26]. As the etymology of the word indicates, 'hysteria' originally defined a neurotic condition peculiar to women and thought to be caused by a dysfunction of the uterus'. By 1839 , the term acquired the general sense of 'unhealthy emotion or excitement' [23]. In a rather Dickensian farcical way, a recent film entitled Hysteria (dir. Tania Wexler, 2011) exposes the extent to which those unscientific theories and methods shaped the cultural and social discourse in Victorian England. 
For him, 'Water, unless in combination with alcohol, is poison to you'. Having sentenced thus, he utters a rather peculiar verdict:

Slap: A most debilitated pulse - taking away water - great want of coagulum - lymphatic to an alarming degree. Stamina (strikes him gently) decidedly weak ... The crassamentum of your blood is injured by too much water. How shall we thicken, sir? (Produces bottle.) By mustard and milk ... Exhibited with a balsam known only to myself. (Aside) Rum! (Aloud) Single bottles, one guinea, case of twelve, ten pounds. [10: 53]

Well versed in the medical lingo disseminated through specialized literature, Slap is a charlatan determined to 'metaphorically bleed' [10: 34]the apparently gullible Nightingale. The scene is typically Dickensian in tone and setting and it reiterates the con doctor-credulous patient dynamic found in other works in which the author is equally ungenerous to medical practitioners. The doctors he portrays are hardly able to do their job, nor do they seem to be people of 'good sound sense' [24: 20]. Dickens's doctors are 'weak and rather silly' [24: 21], and they are often unworthy of their patients' trust. Lack of trust in professionals and their professed science meant that the quality of medical practice in Victorian England was highly dubious. There was a serious 'discrepancy between the criteria used by the public to evaluate a potential therapist and those which the medical community used, or proposed to use among themselves' [11: 598]. Consequently, 'the challenge was to bring the public notion of medical authority into line with doctors' own definition of expertise' [15: 599].

\subsection{For a reform of medicine and of the medical profession}

The patient-doctor relation was a major issue at the time and it was central to current debates on the medical reform. Patients were still treated as invalids and they were widely confined to a passive role; this was especially true of female patients, as Harriet Martineau amply demonstrated in her work, especially her 1844 essays. Another major issue was the popularity and dissemination of improbable therapies, of which the 'chalk and pea flour' and the 'mustard and milk' remedies cited in the play [10: 53, 55] are a clear example, not to mention the extortion of money from vulnerable people whose fate was literally in the hands of equally improbable doctors.

A true reform of medicine and of the medical profession would begin with a public reflection on current misconceptions and the incidence and gravity of misdiagnoses ${ }^{7}$. The social construction of disease (and of the diseased), on the one hand, and the social construction of

7 The case of epilepsy is emblematic: as Larner observes, 'The conflation of epileptic seizure with mental illness [was] typical of 19th century conceptions of epilepsy' [5: 423]. Dickens, who evidently knew the difference and was alert to medical misconceptions, codified faints and fits in his work so that 'faints seem to afflict 'good' characters ... while 'bad' characters have fits ... and good characters are women and children while the bad ones are men' [5: 424]. medicine itself, on the other could no longer be overlooked. The two, inevitably, went hand in hand, and Dickens - the writer and the social reformer - knew it all too well as he strove to change the way in which people conceived of and of healing matters.

Mr. Nightingale's Diary belongs to such an aesthetic and ideological design. The play stages the vulnerability and naivety of those like Nightingale, who couldn't believe that 'there are people base enough to trade upon human infirmities' [10: 62], though the opposite was worryingly true. While Flormiville forbids the intake of water, Gabblewig (disguised as Captain Blower) appears on the scene 'as a great invalid' [10:64]:

Gabblewig: I can't walk any farther ... a quarter of a mile, that's a day's journey to a man in my condition ... I've tried everything.

'Perhaps not everything' says Slap/Flormiville, who proceeds to give out yet another improbable medical opinion:

'Pulse very debilitated; great want of coagulum; lymphytic to an alarming degree; stamina weak - decidedly weak ... crassamentum queer. No hope but in mustard and milk'. [10: 65]

Slap/Flormiville keeps repeating the only diagnosis he evidently knows while Gabblewig is the living proof of the devastating effects of the mustard-and-milk therapy. In the scene that follows, the two engage in a fight that ends with the former's departure and the latter's victory. The bad lose and the good win, to everyone's contentment, but the audience is left with a somber feel as it suddenly becomes aware that trust is easily betrayed and deceit is hardly avoided. The play ends with a clear suggestion that Nightingale is not, after all, a hopeless case. Prepared to burn his Diary, like Prospero with his books of magic in The Tempest, Nightingale will destroy that long-time record of alleged symptoms and fake remedies. With that he will discard his life-long imaginary poor health symbolically putting an end to the system which enabled its coming into existence.

\section{Conclusions}

By 1851, the reform of medicine and of the medical profession was well under way in England. Dickens's contribution to that important phase in the social and medical history of his country would be acknowledged, however partially, twenty years later, upon the writer's death, in an obituary which contemplated 'the gain' that it 'would have been to physics if one keen to observe and facile to describe had devoted his powers to the medical art' [25]. To this day, tribute articles testify to the impact of Dickensian diagnoses upon nosology and the development of theoretical and 
empirical studies on a variety of pathologies ${ }^{8}$. Dickens's endeavor towards a reform of public health and sanitation and towards the construction of health institutions and shelters, some of which are still extant, such as the Urania College, Great Ormond Street, and The Lancet in London [27], deserves equal praise ${ }^{9}$. As a writer socially committed he did not attack medicine per se nor did he favor alternative treatments as exclusive approaches to healing. In the view of a man as he was at the time, with a distinctive and practical knowledge of medical matters, both biomedicine and the so-called unorthodox medicine were capable of bringing solace to the ill but they were also limited in their power to guarantee the good of all. What came under Dickens's scrutiny and increasingly became targeted both in his speeches and literary works were ideologies and practices that turned illness into a speculative affair and consecrated medicine conveniently as a new religion. In this respect, the theatrical medium allowed him to stage and expose public discourses concerning both patients and their doctors, while also denouncing social inequality, the hopelessness of Victorians' phobias and fads, and the often thin divide between medical earnestness and mendacity in disguise.

\section{REFERENCES}

[1] M. Davies. Did Charles Dickens really save poor children and clean up the slums?, 7 February 2012, at http://www.bbc.com/news/magazine-16907648

[2] J.E Cosnett [2012], 'Dickens and Doctors: Vignettes of Victorian Medicine', at www.seniorwomen.com/news/index .php/dickens-and-doctors.vignettes

[3] R. Richardson. The art of medicine. Charles Dickens, The Lancet, and Oliver Twist. In The Lancet, Vol. 379, February 4, 404-405, 2012.

[4] K. Boehm. Charles Dickens and the Sciences of Childhood: Popular Medicine, Child Health and Victorian Culture. Basingstoke: Palgrave, 2013.

[5] A.J. Larner. Charles Dickens (1812-1870) and epilepsy. In Epilepsy and Behaviour, No. 24, 422-425, 2012.

[6] F. Kaplan. Dickens and Mesmerism. The Hidden Springs of Fiction. Princeton, NJ: Princeton University Press, 1975.

[7] G. Storey, K. Tillotson, and N. Burgis (eds). The Pilgrim Edition of the Letters of Charles Dickens. Vol. 6: 1850-1852. Oxford: Clarendon Press, 1988.

[8] R. McGrew. Irregular medicine, hydropathy. In Encyclopedia

8 These include aphasia, epilepsy [26, 3], sleep breathing disorders, also called 'Pickwickian syndrome' [26], movement disorders (spasmodic dysphonia, functional medical disorders, Tourette's syndrome, cervical dystonia, essential tremor, ataxic gait, Parkinson's disease, restless leg syndrome) [28], tuberculosis, chronic bronchitis, asthma, cerebellar ataxia, supernuclear palsy, stroke, cholera, and the complications of alcoholism [27].

9 Dickens's Speech on Sanitary Reform in London, delivered on May 10, 1851 , [30] is a precious testimony of the writer's commitment to these causes, and it is interesting to note that he wrote that address at the same time as when he was also working on Mr. Nightingale's Diary. of Medical History. London: Macmillan, 1985.

[9] N. Gevitz. Unorthodox medical theories. In W.F. Bynum, and R. Porter (eds), Companion Encyclopedia of the History of Medicine, Vol. 1. London: Routledge, 1993.

[10] C. Dickens. Mr. Nightingale's Diary. A Farce in One Act. Boston: James R. Osgood \& Co., 1877.

[11] M. Foucault. The Birth of the Clinic. Transl. by A.M. Sheridan. London: Tavistock Publications, 1973.

[12] L. Salis. Dickens e ilteatroritrovato. In Dickens. Teatro. Tissi - SS: Angelica Editore, 13-24, 2013.

[13] J. Glavin. Dickens and Theatre. In J.O. Jordaned. The Cambridge Companion to Charles Dickens. Cambridge: CUP, 189-203, 2001

[14] W. Cullen, First Lines of the Practice of Physic. Edinburgh, 1791. The Online Etymology Dictionary athttp://etymonline .comindex.php?allowed_in_frame $=0 \&$ search $=$ hypochondria

[15] A. Winter. Harriet Martineau and the Reform of the Invalid in Victorian England. In The Historical Journal, Vol. 38, No. 3, 597-616, 1995.

[16] H. Martineau. Life in the Sickroom: Essays. By an Invalid. London: Edward Moxon, 1844.

[17] S. Connor. All I Believed Is True: Dickens and the Mesmerism System. A talk given at Dickens and Science, Dickens Day, Birkbeck College, London, 10 October 2009, available online at http://www.stevenconnor.com/mesmeris $\mathrm{m} /$ mesmerism.pdf

[18] C. Dickens. The Letters of Charles Dickens: Vol. 4: 1844-1846, K. Tillotson ed. Oxford: Clarendon, 1977.

[19] T. Nichols. How to Behave. A Manual of Manners and Morals. London: Longmans, 1868.

[20] J. Hill, M.D., Hypochondriasis. London, 1766. The Online Etymology Dictionary at http://etymonline.comindex.php?al lowed_in_frame $=0 \&$ search $=$ hypochondria

[21] S. Nettleton. The Sociology of Health and Illness. Cambridge, Polity Press, 1995.

[22] C. Yuill. Concepts of health and medicine, 20-30, 2011. Available Online at http/www.sagepub.com/upm-data/43876 9781446201886.pdf

[23] 'Hysteria'. The Online Etymology Dictionary, http://www.etymonline.com/index.php?term=hysteria

[24] J.C. Dana. The medical Profession as seen by Charles Dickens. In Medical Libraries, Vol. 1, no. 4, 19-21, 1898. Available Online at http://www.ncbi.nlm.nih.gov/pmc/articles/PMC20 47411/pdf/medlib00048-0007.pdf

[25] Dickens. Obituary. In British Medical Journal, 1870: 636.

[26] J.E. Cosnett. Dickens and Epilepsy. In Epilepsia, No. 35, 903-905, 1994.

[27] M.H. Kryger. Charles Dickens: Impact on Medicine and Society. In Journal of Clinical Sleep Medicine, Vol. 8, No. 3, 2012.

[28] K.L. Schoffer, and O'Sullivan. Charles Dickens: the man, medicine, and movement disorders. In Journal of Clinical Neurosciences, Vol. 13, No. 9: 898-901, Nov. 2006.

[29] H. Markel. 'Charles Dickens' work to help establish Great Ormond Street Hospital, London', in The Lancet, vol. 354, pp. 673-675, 1999. 
[30] C. Dickens. Speech on Sanitary Reform in London. In Speeches Literary and Social. Auckland, NZ: The Floating Press, 254-257, 2015. 